\title{
NPS and the Methadone Queue: Spillages of Space and Time
}

Liviu Alexandrescu

\section{Background}

Between 2008 and 2013, powder-stimulants sold by 'head shops' as novel psychoactive substances (NPS) or 'legal highs' have displaced heroin among groups of injecting substance users in Bucharest, Romania. Rising HIV-infection rates and other medical or social harms have been reported to follow this trend.

\section{Methods}

The study builds on two sets of original $(\mathrm{N}=30)$ and existing $(\mathrm{N}=20)$ interview data and on observations collected mainly at the site of a methadone substitution treatment facility.

Results

By disentangling the space-time continuum of the methadone queue, this paper argues that injecting drug users' (IDUs) passage from opiates to amphetamine-type stimulants (ATS) can be understood as 'spillages' of space and time. IDUs thus 'spill' out of the disciplinary flows of methadone treatment in two ways. The first is that of space and materiality. Drawing on actor-network theory (ANT), ATS/NPS appear embedded in reconfigured practices and rituals of injecting use. Such spillages see the pleasure-seeking self being fluidised in forming connections with, or spilling into, nonhuman actants such as substances, settings or objects. The second dimension of spilling is that of time. In this sense, heroin use is a 'cryogenic strategy' of inhabiting history and facing the transition to the market society that Romanian opiate injectors spill out of, not able to appropriate choice and legitimate consumption. The phenomenological qualities of stimulants that seem to accelerate lived time and generalise desire thus present them with an opportunity to alleviate a form of what a post-communist moral imaginary of transition frames as debilitating nostalgia.

\section{Conclusion}

ATS/NPS are revealed as fluid entities that do not only shape risk conditions but also alter shared meanings and contextual configurations of bodies, substances and disciplinary regimes in unpredictable ways. 


\section{Introduction}

The distribution of novel psychoactive substances (NPS) or 'legal highs' on a global scale has prompted panic reactions and various scheduling measures. These were meant to counteract the dangers of myriad forgotten or unknown, revived or newly synthesised compounds sold by 'head shops'. Such hazards have been generally situated within risk economies threatening the wellbeing of neoliberal subjects. This paper aims to connect NPS use with wider webs of meaning and social-historical transformations beyond the logic of the risk society (Beck, 1992; Giddens, 1991). To this purpose, it focuses on a group of injecting drugs users (IDUs) transitioning from heroin to amphetamine-type stimulants (ATS) sold by NPS retailers in Bucharest, Romania. Between 2008 and 2013 the country witnessed a consistent rise in HIV-infections among its intravenous drug using population (Botescu, Abagiu, Mărdărescu, \& Ursan, 2012; NADA, 2014). Such trends were suggested to accompany the increasingly erratic behaviour of ATS injectors.

The study presented here draws on interview and observational data collected mainly around a methadone clinic to understand the migration from heroin, the main substance of choice for Romanian IDUs, to ATS/NPS. In doing so, it reads the methadone queue as a disciplinary device, and separates its spatial-temporal flow into 'spillages' of space and time. In the dimension of space, it uses actor-network theory (ANT) to point to the pleasures of fluidising the self in sensual connections with substances, settings and objects. In being resolidified from such spillages, the self can also face the disorder of sickness or dissolution. In the dimension of time and historical transition, the phenomenological qualities of stimulants indicate an acceleration of historical progression and an expansion of desire. They thus seem to allow heroin users stuck in frozen or 'cryogenic' time to move on along with the whole of post-communist Romanian society in its transition to consumer capitalism. Highlighting NPS as a fluid object of policy, the paper ultimately questions the limits of pleasure and health, risk and consumption as ordering principles of life in the late modern capitalist world.

\section{The methadone queue}

The author of this paper has elsewhere (Alexandrescu, 2016) looked at injecting NPS users as a counterpublic (Duff \& Moore, 2015; Race, 2009; Warner, 2002) trying to 'normalise' their identities and shake off the stigma of drug abjection. This would be done by using what initially seemed like legitimate commodities sold in apparently regulated retail 
spaces they could invest with open meanings. Such observations are also relevant for a critical discussion of the methadone clinic as a dispositif or disciplinary apparatus (Foucault, 1980). Targeting populations that do not manifest the health needs of a mainstream public presumed to be sober or 'clean' - counterpublics of injecting opiate users - substitution programmes point to a wider biopolitics (Foucault, 1990) of addiction management (Neale, 2013). They attempt to reposition subjects into rational and productive lifestyles (Bennett, 2011; Bergschmidt, 2004; Bourgois, 2000; Neale, Nettleton, \& Pickering, 2013).

Foucauldian analyses of methadone maintenance treatment (MMT) have highlighted that any conceptualisation of the problematic drug user cannot exist "outside of the clinics, programs and other disciplinary regimes which produce it" (Keane, 2009, p.452). For Bull (2008), substitution treatment is a strategy to regulate the supply side of uncontrolled substance markets. Bourgois (2000) argues that methadone prescription is not separable from normative expectations of employment and income generation to reconstruct its beneficiaries' social-cultural identities. Friedman and Alicea (2001) discuss heroin use and MMT in terms of resistance to traditional gender roles, paralleling patriarchal oppression and medical bureaucracies in their requirement for conformity. Fraser and Valentine (2008) indicate that notions of health, autonomy and social participation intersect to shape the subjectivity of the methadone client (see also Pedersen, 2002; Smith, 2011; Valentine, 2007).

Of particular importance here is Fraser's (2006) work on the chronotope of the methadone queue. Drawing on Bakhtin's (1981) theory of the chronotope or space-time unit of literary narration, Fraser argues that the dosing point also produces disciplined patients along with the requirement to line up and wait for the collection of their daily dose. Spatial and temporal flows spiral into each other in the queue to redirect the waiting and the substance using subject from the black market to the regulated setting of treatment. As such, "rather than gaining access to a new and liberating lifestyle, treatment can, under certain conditions, merely shift the waiting, the service, the attentiveness, from the illicit drug market to the licit drug market" (Fraser, 2006, p.200). The client waits for the drug worker instead of waiting for the dealer, replacing the unpredictability of alley exchanges with the controlled setting and timetables of the clinic. S/he is discouraged from troubling public order and redirected towards the labour demands of the market economy.

The methadone queue is also meant to act on the failed reason-exerting liberal subject who fails to correctly appropriate freedom by embracing addiction (Reith, 2004). Opiate users 
stand as bad choice-makers who cannot be governed like other publics because they refuse the liberating calling of choice in allowing themselves to be robbed of their will (O'Malley \& Valverde, 2004; Sedgwick, 1994; Seddon, 2010). Choosing to refuse and abandon choice, they thus refuse to make themselves visible to social structures that can only function by monitoring their choice-making behaviours (Rose, 1999). By channelling, measuring and routinising substance use, substitution treatment puts forward a platform for a sacrificial ethic of treatment to foster addicts' agency in working on their broken selves.

In what follows, the chronotope of the methadone queue is broken and the liquidities ('flow' and 'spillage') metaphor(s) used to understand how injecting NPS users would see in the new drugs and the shops that sold them a possibility of escaping the containment of treatment flows and speeding up their recovery through will-affirming desire and choice. Drawing on literatures from the fields of science and technology studies and post-communist nostalgia, a sociological discussion of the harms attributed to emerging drugs will reveal these as residual manifestations of the very discourses of harm-aversion and ensuing practices that current drug control models are largely built on.

\section{Method}

The data used here come from two sets of semi-structured interviews. An original set of 30 interviews was collected between April and September 2012 and mostly focused on a low threshold methadone clinic in Bucharest, Romania. It included 15 injecting substance users who had developed sustained habits of ATS/NPS use that they had either replaced of alternated heroin with and 12 'specialists' (drug/outreach workers, activists or policy makers) who had observed transformations in local substance markets throughout the preceding years. Three journalists who had been directly involved in the reporting of the NPS phenomenon were also interviewed, to supplement a corpus of around 600 news items that will be discussed in a separate paper.

The sample was generated through convenience and snowballing sampling. Three interviewees were known to the author. A further 22 were identified with the initial or other participants' help (this was the case with all the NPS users interviewed) and a further five by the author himself - approached either directly or through the mediation of other participants. The main body of data was supplemented with on-site observations of daily life in the methadone clinic, where 17 of the 30 interviews were recorded. 
The youngest of the 15 users were in their early twenties at the time of being interviewed and the oldest were approaching their mid-thirties. All had used heroin previously to NPS for at least five years. Only two of them were females. Most came from underprivileged backgrounds. Three of them (all males) had been sleeping rough for significant periods of time. The socio-demographic profile of this sample corresponds to what the country's National Anti-Drugs Agency (NADA, 2013, 2014) had identified as the keysubpopulation of IDUs among which the new powder stimulants had shown their deepest penetration. Of the 12 specialists interviewed (ages varying from late twenties to early fifties, a third of which females), four were working at the methadone clinic under focus, five were coordinating various care and counselling facilities, two directed third sector organisations that ran advocacy programmes and one had been a top-tier policy maker.

The doctoral project served by the data discussed in this study was approved by Lancaster University's Research Ethics Committee. Information sheets and consent forms were presented to recruited participants, brief interview guides progressed from individual experiences and exposure to NPS use to larger considerations of their impact on the drug scene and in the fields of treatment and policy. The interviews were both topical and cultural (Rubin \& Rubin, 1995), dealing with the specific permeation of NPS in the country, as well as with more general views of old and new drugs in the collective imaginary of post-communist Romanian society.

The data were processed through a combination of theoretical and constructionist thematic analysis (Braun \& Clarke, 2013). In the former sense, the coding of the data was influenced by the initial theoretical assumptions of the doctoral project (guided by a revised model of moral panic theory), looking at notions of medical and social harm, disproportionality and stigma. In the latter sense, a different direction (along with more 'spontaneous' or grounded codes) emerged in looking at the conceptual construction of experiences and narratives of NPS use by the interviewees. The points discussed here emerged in this manner. An important caveat should position the two main constituencies of participants as stakeholders in the production and distribution of 'assumed knowledge' (Coomber, 1997) - users as beneficiaries of treatment possibly attempting to justify their entitlement to care by replicating notions of harm and sickness, care givers and other 'specialists' as an interest group legitimating their position, further claims for funds and recognition. 
The main themes were cross-matched with an existing set of 20 interviews collected in the spring of 2013 for a study on the policy challenges posed by NPS and the new drugs trade (Sarosi, 2014). It comprised 15 experts (clinicians, harm-reduction providers etc.), along with users of various NPS and peers. The paper will make use of selective quotes while referring to some of the key-themes and insights identified. This means not putting forward a descriptiveexhaustive discussion of all the relevant findings but dealing mostly with the main theoretical points of interest.

\section{Findings}

Participants hinted at four types of incentives that pushed experienced heroin injectors to experiment with, and eventually develop habits of using, the powder-stimulants sold by 'dream shops' - as the Romanian media called NPS outlets. The first was their perceived safe legal status. This meant escaping police harassment and avoiding, or not adding to, a criminal record. The second was their mysterious pharmaceutical nature. Substances referred to by media outlets as 'legal drugs', 'legals', 'ethnobotanical substances' or 'ethnobotanicals' terms initially proposed by retailers to conceal the nature of the trade - left room for various meanings. Some heroin users almost saw them as medicine for their opiate withdrawal sickness and shops as state-sanctioned dispensaries. Many talked about an opportunity to be 'normal' again. The third incentive was found in the price and easy availability of supply. At a time when heroin was scarce on the streets, being able to sell consistent stocks at considerably lower prices than the street market made 'dream shops' successful business enterprises. Finally, the fourth referred to the psychoactive qualities of ATS like synthetic cathinones that at least in the beginning allowed opiate users to experience different but generally euphoric states of 'high'.

Through all these strategies of making sense of the 'legal high' phenomenon, NPS emerge as a fluid object that cannot be easily defined and contained. Between the presumably faraway laboratories that produced them and the local shops that sold them, drug laws and police surveillance, news reports, streets and clinics, definitions of what NPS were and why they were easily and abundantly accessible also varied widely and created confusion among care givers and patients. In their multiplicity or fluidity as chemical and cultural artefacts, ATS/NPS escaped simple conceptualisations of causality - properties of, or harms caused by, any of the individual labels and substances behind them proved almost impossible to separate 
from the bulk. One attempt to stabilise them as a knowable category was to start profiling a problematic figure of the NPS user, who in compulsive desire was predisposed to develop psychotic tendencies, turning into a source of disruption to treatment. Such mutations and reactions to them can be understood by imagining two ways of engaging states of firmness and liquidity.

\section{Spillages of space}

Formlessness or liquidity appears problematic to a dominant understanding of the "self as the moral locus of consumption" (Race, 2009, p.15). Actor-network theory (ANT) (Latour, 2005; Law, 2009; Mol, 2010) rightly hints at the pleasures of substance use being located in acts of 'letting go' and 'coming back' that see the self surrendering to the sensuality of substances, spaces and objects that it shares agencies with (Duff, 2012). Such 'passings' from effects sought by the human to effects done to the human (Gomart \& Hennion, 1999) open up multiplicities of being that lead to reconfigurations of bodies and substances - the alcohol that causes violence in one context may not do or be the same in another (Demant, 2013), the methamphetamine which leads users into psychosis may encounter another context where it does not (Dwyer \& Moore, 2013). As "fluid, shape-shifting and name-changing objects" (Law $\&$ Singleton, 2005, p.340), drugs afford the separation of the unified solid self from the linear flows of hard rationality.

The ANT toolbox contributes to a concept of fluid agency that is spilled back and forward between human and nonhuman actants. In this sense, such spillages of space are transformative experiences through which bodies can explore their own fragile boundaries, in losing shape and recomposing themselves. This can be traced back to the initial temptation of NPS. As multiplicities of unknown 'white powders' sold in vividly coloured packets under playful labels, NPS, 'legals' or 'ethnobotanicals' opened up multiplicities of both accidental and intentional crossings of boundaries. Some saw in them a possibility of healing and escaping opiate withdrawal pains. They encouraged pleasurable experimentation and the fabrication of new meanings. A 28-year-old male heroin user's adventure with NPS, for example, began as a rescue mission. In trying to discourage his girlfriend from using them and make her go back to heroin, he first had to understand what she felt. 
I did those three lines [syringe units], I couldn't feel anything. I was lying on the grass, on my back. When I got up, I felt that I was walking on air. I was walking all by myself and I liked it: "Give me another three lines, give me another three lines!"

In the days that followed he walked the streets for hours on end, fuelled by a strong wave of energy and mental stimulation. He would see things with a newborn's curiosity, as if he had not really seen them before. This sense of pleasure through movement would allow him to turn space into place, as if he belonged to the streets and the streets belonged to him (Duff, 2007; Keane, 2011). The same sense of perpetual effervescence was also what made another male user (29 years of age) think that these were the drugs that he had been looking for since his first teenage experiments. In trying a few lines of (the mephedrone-based) Magic and Special Gold, he allowed himself to be surprised once more, as had happened with heroin years back.

I started to see everything glowing. The colours were very vivid. There was a sense of euphoria growing in me. I was in the mood for music.

In looking at such meaningful insights one can talk of purifying spillages. NPS seemed, however, to also be part of what could be understood as toxic spillages. It was mainly after the adoption of new scheduling measures banning more than 40 compounds identified as NPS (in 2010) that most users and clinicians pointed to the intensification of health problems associated with the new stimulants. Cardiac strain and infections (endocarditis) caused by frequent injecting, exposure to unsanitary settings and contaminated needles, or mental breakdown following days-long bingeing sessions without sleep and proper nutrition were reported (consistent with Botescu, 2012; Botescu et al., 2012; NADA, 2013, 2014).

The 'speed psychosis' that NPS users experienced could not be separated, however, from the surveillance and repressive enforcement practices that drove psychoactive substance use underground. Many injectors' obsessions and paranoid thoughts fed on the constant fear of being caught, beaten and humiliated by the police. One remembered that in his lowest moments on NPS he convinced himself that the mother of his six children was working with undercover agents to throw him in prison. Following this, he held a knife to her throat in a fit of paranoia. Another male and homeless injector (29-years-old) believed that he got infected with HIV right outside a head shop, as he and a friend who had been diagnosed before were preparing to shoot a powder they had just bought. 
The police were thirty meters away from us and I had started to shake. I was so scared that I was shaking. I was scared that they were going to catch me and throw it away. And I told him: "Give me your syringe now!" [...] and injected it all. Put in into my vein. And I was aware that I was going to get it [HIV] but it was that desperation that made me shoot it as fast as possible.

As they attracted customers but also heavier police presence, NPS and 'dream shops' also contributed to the reworking of urban topographies of risk and desire. If the flow of the needle is meant to channel and order experiences in rational and sanitary ways, its eventual hijacking into compulsive desire could result in the ontological mess of infection or even dissolution. Toxic spillages can be total events that wipe out former orders of elements.

NPS would also pass and spill between 'dream shops' and dark market flows. As some were banned and others took their place, they would be absorbed into underground econonomies. A medic prescribing methadone to IDUs detailed how street dealers had seized the opportunity trying to engage clients by moving operations near slot machines and onto other leisure spaces, offering them a 'hit' from a syringe into which they had dissolved a whole packet of five or more doses. They would thus inject as many buyers with the same needle to maximise profit margins. Sales strategies of this kind further separated users from the syringe. More so, many drug workers further suggested that quite often the heroin sold on the streets was cut with powder stimulants, exposing those who bought it to the hazards of unwanted experiments with the resulting 'speed balls'.

A forensic pathologist described NPS users as 'injecting machines'. Care providers working with them suggested that they could inject as much as three times more frequently than they did on heroin. A 30-year-old male NPS user suspected that he got infected the one time when he did not have his own syringe on him and had to share with 'one of the few' other users in his entourage whom he trusted. Another 24-year-old male user and rough sleeper for years explained that to inject he would dissolve the contents of his ATS sachets into 'anything, from orange juice to puddle water'. He also described paranoid thoughts and violent reactions, recounting how on one ocassion as he was injecting in a stairwell he poked another user in the forehead with the needle that the other had been repeatedly asking him for. 
I was walking down the street [after it happened] and it seemed like everyone turned their backs on me, you know. And this pissed me off, you know. I shouted: "Why are you staring at me, what do you want?"

Through all these reconfigurations of emotions and materialities there would also emerge a new patient typology that the substitution services would have to work with. If one of the goals of treatment was to pull out heroin users from the emotionless 'bubble' they had retreated into - as a treatment coordinator framed it - the new stimulants would allow them to burst that bubble. But in doing so they could also spill into states that destabilised them as willing participants in the restorative goals of treatment. One outreach worker underlined the paradox that in realising clients in the field would respond to harm-reduction messages even less than before, the only reasonable strategy left was to turn their old drug of choice, heroin, into a harm-reduction tool, and advise them to go back to it. A female therapist (29-years-old) explained how her approach in dealing with injecting NPS users changed as a response to patient noncompliance.

Like hot soup, sleep, talk things through with your loved ones, hot soup, sleep... Like earthly things. I mean I don't work with anything related to understanding the patient's situation anymore because it's too obvious - he or she is on 'ethnobotanicals' and misses nurture, misses affection, misses trust in his or her loved ones.

A concept of material-semiotic 'spillages' can thus reveal a poorly stabilised notion of ATS/NPS whose meanings heroin users would tweak in breaking the disciplinary flows of treatment. Such sensual acts of letting go to new drugs and opening unforeseen ontological avenues could lead to purifying or toxic spillages. In discussing such concepts the limitations of the ANT theoretical vocabulary and its levelling conception of human and nonhuman agencies have to be acknowledged. The human as moral agent still seeks pleasure more than 'agentic' chemical artefacts, settings and devices do. Such a presumed symmetry or parity overlooks humans' capacity to act in language communities (Collins, 2010) and willingly give in to meaningful connections or assemblages of 'intoxicating' elements. ANT reveals that syringes, settings and substances are more than instruments but that their functions order in turn episodes of intoxication. Even if such artefacts can act as 'moralising technologies' (Verbeek, 2011) in interfering with the experiences of the moral subject, the drive to deny the rationality and predictability of the flow and embrace the uncertainty of the spillage is what sets the human apart. 


\section{Spillages of time}

A second strategy of imagining formlessness or liquidity is that which looks into the time flow of the methadone queue and describes injecting substance users as 'nostalgics' or failed transition subjects. Eastern European scholarship on post-communist nostalgia is of use here. Nostalgics are a counterpublic that challenges the "hegemonic condemnation of the past" (Velijonka, 2009, p.540) and the historical project of transition to market capitalism. They can only be the residue of that process.

'Nostalgia' takes on different meanings in the post-communist world. It is understood as a clash of norms between succeeding historical periods (Berend, 2007) or an ideological conflict between generations, also fuelled by the dissipation of the welfare nets that the paternalist soviet states had sustained (Ekman \& Linde, 2005). In a more optimist reading ways of nostalgic remembrance are also 'mnemonic bridges' (Bartmanski, 2011) that connect past and present and allow the collective imagination to move on to visions of a better future (Velijonka, 2009). In Romania and elsewhere in Eastern Europe, however, popular discourses condemn and frame such states as moral pathologies. They suggest that the denial of the past is an ongoing project that all must participate in through firm stances of self-criticism (Georgescu, 2010). The official condemnation of the communist past voted by the Romanian Parliament along with the adoption of the 'Final Report' of the Presidential Committee for the Analysis of the Communist Dictatorship in Romania (PCACDR, 2006) pins this as the only legitimate historical narrative.

An alternative reading sees nostalgia as a way of opting out of transitional history - a 'cryogenic' strategy of freezing transitional time. Popescu-Sandu (2010) refers to this as 'reverse nostalgia', a way of jumping straight into the 'golden age' of capitalism after having failed in that of communism without living through the eerie times that mark the passage. This is also what opiate users appeared to attempt. As incapacitated choice-makers fixating on a dark commodity - often caught into other forms of racial or status marginality (Roma ethnics, lower class, homeless or sex workers) - they would refuse to be liberated by the progressive forces of the market as they refused to appropriate the calling of consumer capitalism. They would embody the worst of western mores. However, it is in the phenomenological qualities of opiates that such a state of being also presented a cryogenic defence strategy. As the French author and filmmaker Jean Cocteau wrote, opium is like a 
season that never changes: "The opium smoker ceases to suffer alterations of time anymore. He never catches a cold" (Cocteau, 1970, p.126).

By freezing individual time, opiates can also freeze historical time. If as a counterpublic heroin users spilled through the time of historical transformations that Romanian society actively engages as a collective moral goal, heroin would allow their hermetic sealing into cryogenic states. Through opiate use they could inhabit their own time capsule that substitution treatment would attempt to break through its ritualised timetables and structured stages. When many went on to use the stimulants sold by NPS retailers, they were also presented with what revealed itself a possibility of accelerating the time of transition. Substances that would enhance awareness and fuel movement also sped up the pace of everyday life in the city for those who used them. Stimulants like mephedrone and various synthetic cathinones, among others, altered the very fabric of drug time, as a male NPS user (29-years-old) explained.

With heroin you get high, you do it today, a 'ball' in the morning, maybe a 'ball' in the afternoon and a 'ball' in the evening, let's say. Well, with that ['Magic' mephedrone] you get high every twenty, thirty minutes. You sting yourself now, sit there a bit and you want that cool sensation again.

It is in this quality of stimulants to impose 'speed time' on the user that the 'speed psychosis' associated with sustained NPS use could be traced. As a 23-year-old female user observed, NPS users wanted more and wanted faster. But this would also alter the timing and quality of everyday rituals of use. Many rushed it in desperation, obsessed with the fear of 'getting burned' by others - having powder stolen from one's packet or swapped with something else.

I never understood this rush for shooting 'legals'. [...] You didn't have time to contemplate anymore, as it happened with heroin. To enjoy it. Everything was happening on fast forward.

Despite this, ATS/NPS would still allow users to tune into the ethos of consumer capitalism better than the 'cryogenic bubble' of opiates. As Lenson (1995) argues, stimulants are the drugs that best emulate the capitalist spirit. They help rework desire and expand it to the point where its objects can only be pinned down for a split second. This is spilled desire that becomes a permanent condition but that also brings the user's time in synchronisation 
with the more general time of capitalist consumption. In opening up appetites, it also opens up possibilities of participation in the pleasure economy. Such possibilities would also be made more obvious by the hedonistic imagery of supposedly regulated retail spaces that head shops displayed. Inside, 'nostalgics', failed choice-makers or 'frozen' transition subjects, IDUs would be able to exert legitimate choice as legitimate consumers. A 33-year-old male drug worker pointed to this paradox.

If you had desperately wanted to try drugs at that time what would you have tried? Would you have tried whatever drugs bought from a dodgy dealer or gone to a civilised shop where you could pay for a product which was probably OK?

Buying products that were serially packaged and moved through cash registers would not defy the risk aversion of consumer capitalism but affirm it, while positioning buyers as rational citizen-consumers. But continuous desire would not only lead into what looked and felt like controlled consumption spaces but also into waste spaces and abject conditions. Many talked about NPS users' rapid degradation resulting from the brutal contrast between delusional desire and the harsh realities of life at the margins. Some were said to become garbage scroungers. A 31-year-old male participant claimed that every time he used he would rummage through "every dumpster I could find", looking for an unknown something. Another 27-year-old male NPS user did not admit to doing it himself but tried an explanation for why others would.

It gives them a sort of... state of mind. Deep inside, they think they'll find something valuable. Inside their mind, they know that someone threw away something valuable, somewhere. Not knowing where, they look for it everywhere.

Through such spillages of augmented desire injecting NPS users would also be sucked into spillages of time, negating treatment and its sacrificial ethic of recovery. Addiction treatment affirms the choice-making self and affords a projection into a healthy but laboured future, as opposed to the 'quick fix' of opiates that nullifies any potential future (Klingemann, 2000). Methadone time functions in opposition to addiction time, which appears as lost subjectivity and the negation of the addict's future (Reith, 1999). But the 'speed time' of 'dream shops' and ATS/NPS would ultimately stand in opposition with methadone treatment in shaking up the queue and promising to blast users into an instant, ready-made future. 
The methadone clinic as a disciplinary apparatus geared towards correcting 'cryogenic states' attempted to realign production (recovery as sacrificial labour) and consumption (the return to 'legitimate' desire). Head shops eased the laborious reconstruction of a health identity by not denying the 'easy', non-productive pleasure of the 'quick fix', but only substituting it with the pleasures of a different chemical horizon. In choosing this escape route a counterpublic of 'reverse nostalgics' like NPS users would unfreeze their 'cryogenic time' only to be spilled out of history again.

\section{Significance}

In the goal-oriented, fast-paced and highly ordered human environments of late modern times, intoxication is "a kind of unmaking or decomposition" (Yardley, 2012, p.24) of the socially constituted body that trains itself to be competent in dosing resource expenditures and strengthening instrumental capacities for survival and competition. To experience the world through calculation and utility-value leaves fewer possibilities open for explorations in transgression and communion. But an interrogation of transactional notions of health and wellbeing, and further on of linear explanations of drug-related harms crystallises deeper forms of alienation and disconnectedness.

Those suffering from their NPS use appear as neither culprits nor victims, as neither bad choice-makers nor morally feeble. They emerge as meaning-seekers not trying to isolate themselves from the world around them but desperately trying to understand and connect with it. Giving in to unknown stimulant-powders can be seen as a way of resisting riskmanagement strategies in experimenting with the unpredictable but also as a way of normalising the self, consuming rationally and with purpose to 'heal' oneself and push one's time in line with society's clock time in all the ways discussed above. In further connecting with such struggles, platforms of research and treatment can also articulate possibilities of reform and strategies of resistance to the disciplinary reflexes of the global drug control system. 


\section{Conclusions}

This paper has looked at a broken chronotope (space-time flow) of the methadone queue to show how, as a fluid notion, NPS would be invested with different meanings. Through spillages of space and materiality, users would give in to the pleasures of unpredictable encounters with chemistries, places and needles. These could lead to insightful configurations, as well as dangerous crossings of boundaries into the ontological disorder of psychosis or infection. Through spillages of time and history, heroin turned ATS/NPS users would see a possibility of exiting 'cryogenic time' and being propelled into the future as rational, choice-making consumers. Their newly acquired appetites and desires denied the sacrificial ethic of treatment but could also seal them into sickness and other degrading states.

Invoking liquidity metaphors also presents an opportunity of engaging both the possibilities and dangers of emerging drugs. One way to do this is by placing notions of risk into larger moral arenas and wider contexts of structural transformations. Mutations within drug using lifestyles and cultures can thus be read as responses to the strains of riskmanagement strategies. Drug policy also needs to situate such contingencies within more flexible webs of meaning of how old and new drugs are used and understood to empower substance-using subjects more than prohibitionist responses have traditionally been able to. Notions of risk more closely connected with the pleasures and seductions of unpredictable encounters with drugs are also needed to explain the appeal of new compounds to generations of experienced and experimental users. It is ultimately the solid rationality and predictability of life in the risk society that allow formlessness and liquidity to present themselves as a therapy to the ills that haunt the late modern spirit.

\section{Conflict of interest}

The author declares no conflict of interest. 


\section{REFERENCES}

Alexandrescu, L.G. (2016). Injecting ATS/NPS use and drug abjection in Romania. Drugs and Alcohol Today, 16, 142-149.

Bakhtin, M. (1981). The dialogic imagination: Four essays. Austin: University of Texas Press.

Bartmanski, D. (2011). Successful icons of failed time: Rethinking post-communist nostalgia. Acta Sociologica, 54, 213-231.

Beck, U. (1992). Risk society: Towards a new modernity. London; Newbury Park, California: Sage.

Bennett, C. (2011). Methadone maintenance treatment: Disciplining the 'addict'. Health and History, 13, 130-157.

Berend, I.T. (2007). Social shock in transforming Central and Eastern Europe. Communist and Post-Communist Studies, 40, 269-280.

Bergschmidt, V.B. (2004). Pleasure, power and dangerous substances: Applying Foucault to the study of 'heroin dependence' in Germany. Anthropology and Medicine, 11, 59-73.

Botescu, A. (2012). Risk assessment of new psychoactive substance consumption among children and youth in Romania. Bucharest: Alpha MDN Publishing House.

Botescu, A., Abagiu, A., Mărdărescu, M., \& Ursan, M. (2012). HIV/AIDS among injecting drug users in Romania: Report of a recent outbreak and initial response policies. Retrieved $17^{\text {th }}$ of July 2015 from http://www.emcdda.europa.eu/attachements.cfm/att_192024_EN_HIV_outbreak_Rom ania_2012.pdf.

Bourgois, P. (2000). Disciplining addictions: The bio-politics of methadone and heroin in the United States'. Culture, Medicine and Psychiatry, 24, 165-195.

Braun, V., \& Clarke, V. (2013) Successful qualitative research: A practical guide for beginners. London: Sage.

Bull, M. (2008). Governing the heroin trade: From treaties to treatment. Ashgate: Aldershot. 
Cocteau, J. (1970). Opium: Journal d'une desintoxication. Paris: Stock.

Collins, H. (2010). Humans not instruments. Spontaneous Generations: A Journal for the History and Philosophy of Science, 4, 138-147.

Coomber, R. (1997). The adulteration of drugs: What dealers do to illicit drugs, and what they think is done to them. Addiction Research, 5, 297-306.

Demant, J. (2013). Affected in the nightclub: A case study of regular clubbers' conflictual practices in nightclubs. International Journal of Drug Policy, 24, 196-202.

Duff, C. (2007). Towards a theory of drug use contexts: Space, embodiment and practice. Addiction Research and Theory, 15, 503-519.

Duff, C. (2012). Accounting for context: Exploring the role of objects and spaces in the consumption of alcohol and other drugs. Social and Cultural Geography, 13, 145-159.

Duff, C., \& Moore, D. (2015). Counterpublic health and the design of drug services for methamphetamine consumers in Melbourne. Health, 19, 51-66.

Dwyer, R., \& Moore, D. (2013). Enacting multiple amphetamines. International Journal of Drug Policy, 24, 203-211.

Ekman, J., \& Linde, J. (2005). Communist nostalgia and the consolidation of democracy in Central and Eastern Europe. Journal of Communist Studies and Transition Politics, 21, 354-374.

Foucault, M. (1980). The confession of the flesh. In C. Gordon (Ed.) Power/knowledge: Selected interviews and other writings (pp.194-228). New York: Pantheon Books.

Foucault, M. (1990). The history of sexuality: The will to knowledge, Vol. 1. Harmondsworth: Penguin.

Fraser, S. (2006). The chronotope of the queue: Methadone maintenance treatment and the production of time, space and subjects. International Journal of Drug Policy, 17, 192202.

Fraser, S., \& Valentine, K. (2008). Substance and substitution: Methadone subjects in liberal societies. Basingstoke: Palgrave Macmillan. 
Friedman, J., \& Alicea, M. (2001). Surviving heroin: Interviews with women in methadone clinics. Gainesville: University of Florida Press.

Georgescu, D. (2010). “Ceaușescu hasn't died”: Irony as countermemory in post-socialist Romania. In M. Todorova, \& Z. Gille (Eds.) Post-communist nostalgia (pp.155-176). New York; Oxford: Berghahn Books.

Giddens, A. (1991). Modernity and self-identity: Self and society in the late modern age. Stanford: Stanford University Press.

Gomart, E., \& Hennion, A. (1999). A sociology of attachment: Music amateurs and drug addicts. In J. Law, \& J. Hassard (Eds.) Actor network and after (pp.220-247). Oxford: Blackwell.

Keane, H. (2009). Foucault on methadone: Beyond biopower. International Journal of Drug Policy, 20, 450-452.

Keane, H. (2011). The politics of visibility: Drug users and the spaces of drug use. International Journal of Drug Policy, 22, 407-409.

Klingemann, H. (2000). "To every thing there is a season": Social time and clock time in addiction treatment. Social Science and Medicine, 51, 1231-1240.

Latour, B. (2005). Reassembling the social: An introduction to actor-network theory. Oxford: Oxford University Press.

Law, J. (2009). Actor-network theory and material semiotics. In B.S. Turner (Ed.) The new Blackwell Companion to social theory (pp.141-158). Oxford: Blackwell.

Law, J., \& Singleton, V. (2005). Object lessons. Organization, 12, 331-355.

Lenson, D. (1995). On drugs. Minneapolis: University of Minnesota Press.

Mol, A. (2010). Actor-network theory: Sensitive terms and enduring tensions. Kölner Zeitschrift für Soziologie und Sozialpsychologie, 50, 253-269.

NADA (2013). 2013 National report (2012 Data) to the EMCDDA by the Reitox National Focal Point: Romania, new developments, trends and in-depth information on selected issues. Retrieved $1^{\text {st }}$ of August 2015 from 
http://www.ana.gov.ro/rapoarte\%20nationale/en/National\%20Report\%20on\%20Drugs \%202013.pdf.

NADA (2014). Raport național privind situația drogurilor 2014: România, noi evoluții și tendințe. Retrieved $1^{\text {st }}$ of August 2015 from http://www.ana.gov.ro/rapoarte\%20nationale/RO_RN_2014.pdf.

Neale, J. (2013). Opioid pharmacotherapy: Treatment, regimes, constructions and control. International Journal of Drug Policy, 24, e1-e5.

Neale, J., Nettleton, S., \& Pickering, L. (2013). Does recovery-oriented treatment prompt heroin users prematurely into detoxification and abstinence programmes? Qualitative study. Drug and Alcohol Dependence, 127, 163-169.

O’Malley, P., \& Valverde, M. (2004). Pleasure, freedom and drugs: The uses of 'pleasure' in liberal governance of drug and alcohol consumption. Sociology, 38, 25-42.

PCACDR (2006). Raport final - Comisia prezidențială pentru analiza dictaturii comuniste din România. Retrieved $4^{\text {th }}$ of July 2015 from http://www.presidency.ro/static/ordine/RAPORT_FINAL_CPADCR.pdf.

Pedersen, E.H. (2002). Practices of government in methadone maintenance. Outlines. Critical Practice Studies, 4, 61-69.

Popescu-Sandu, O. (2010). "Let's all freeze up until 2100 or so": Nostalgic directions in postcommunist Romania. In M. Todorova, \& Z. Gille (Eds.) Post-communist nostalgia (pp.113-125). New York; Oxford: Berghahn Books.

Race, K. (2009). Pleasure consuming medicine. Durham, North Carolina; London: Duke University Press.

Reith, G. (1999). In search of lost time: Recall, projection and the phenomenology of addiction. Time and Society, 8, 99-117.

Reith, G. (2004). Consumption and its discontents: Addiction, identity and the problem of freedom. The British Journal of Sociology, 55, 283-300.

Rose, N. (1999). Governing the soul: The shaping of the private self, 2nd ed. London: Free Association Books. 
Rubin, H.J., \& Rubin, I. (1995). Qualitative interviewing : The art of hearing data. Thousand Oaks, California: Sage.

Sarosi, P. (2014). The not-so-balanced approach: Policy responses to new psychoactive substances. Retrieved $17^{\text {th }}$ of July 2015 from http://drogriporter.hu/en/nps_report.

Seddon, T. (2010). A history of drugs and freedom in the liberal age. Hoboken: Taylor and Francis.

Sedgwick, E.K. (1994). Tendencies. London: Routledge.

Smith, C.B.R. (2011). A users' guide to 'juice bars' and 'liquid handcuff': Fluid negotiations of subjectivity, space and the substance of methadone treatment. Space and Culture, 14, 291-309.

Valentine, K. (2007). Methadone maintenance treatment and making up people. Sociology, $41,497-514$.

Velijonka, M. (2009). Lost in transition: Nostalgia for socialism in post-socialist countries. East European Politics and Societies, 23, 535-551.

Verbeek, P.P. (2011). Moralizing technology: Understanding and designing the morality of things. Chicago; London: The University of Chicago Press.

Warner, M. (2002). Publics and counterpublics. Public Culture, 14, 49-90.

Yardley, T. (2012). Why we take drugs: Seeking excess and communion in the modern world. Hoboken: Taylor and Francis. 